\title{
New Modalities for the Administration of Inhaled Nitric Oxide in Intensive Care Units After Cardiac Surgery or for Neonatal Indications: A Prospective Observational Study
}

\author{
Philippe Gaudard, MD,* Claudio Barbanti, MD, † Bertrand Rozec, PhD, , Philippe Mauriat, MD, $\S$ \\ Mimoun M'rini, MD, \| Gilles Cambonie, PhD, \ Jean Michel Liet, MD,\# Claude Girard, PhD, ** \\ Pierre Louis Leger, PhD, †† Ziad Assaf, MD, † Pierre Damas, PhD, 㧊 Gauthier Loron, MD, §§ \\ Laurent Lecourt, PharmD, || || Julien Amour, PhD, शף and Philippe Pouard, MD†
}

BACKGROUND: Nitric oxide (NO) has a well-known efficacy in pulmonary hypertension (PH), with wide use for 20 years in many countries. The objective of this study was to describe the current use of NO in real life and the gap with the guidelines.

METHODS: This is a multicenter, prospective, observational study on inhaled NO administered through an integrated delivery and monitoring device and indicated for $\mathrm{PH}$ according to the market authorizations. The characteristics of NO therapy and ventilation modes were observed. Concomitant pulmonary vasodilator treatments, safety data, and outcome were also collected. Quantitative data are expressed as median (25th, 75th percentile).

RESULTS: Over 1 year, 236 patients were included from 14 equipped and trained centers: 117 adults and 81 children with $\mathrm{PH}$ associated with cardiac surgery and 38 neonates with persistent PH of the newborn. Inhaled NO was initiated before intensive care unit (ICU) admission in $57 \%, 12.7 \%$, and 38.9\% with an initial dose of $10(10,15)$ ppm, $20(18,20)$ ppm, and $17(11,20)$ ppm, and a median duration of administration of $3.9(1.9,6.1)$ days, $3.8(1.8,6.8)$ days, and 3.1 $(1.0,5.7)$ days, respectively, for the adult population, pediatric cardiac group, and newborns. The treatment was performed using administration synchronized to the mechanical ventilation. The dose was gradually decreased before withdrawal in $86 \%$ of the cases according to the usual procedure of each center. Adverse events included rebound effect for 3.4\% (95\% confidence interval [Cl], $0.9 \%-8.5 \%)$ of adults, $1.2 \%(95 \% \mathrm{Cl}, 0.0 \%-6.7 \%)$ of children, and $2.6 \%(95 \% \mathrm{Cl}, 0.1 \%-13.8 \%)$ of neonates and methemoglobinemia exceeded $2.5 \%$ for 5 of 62 monitored patients. Other pulmonary vasodilators were associated with $\mathrm{NO}$ in $23 \%$ of adults, $95 \%$ of children, and $23.7 \%$ of neonates. ICU stay was respectively $10(6,22)$ days, $7.5(5.5,15)$ days, and $9(8,15)$ days and ICU mortality was $22.2 \%, 6.2 \%$, and $7.9 \%$ for adults, children, and neonates, respectively.

CONCLUSIONS: This study confirms the safety of NO therapy in the 3 populations with a low rate of rebound effect. Gradual withdrawal of NO combined with pulmonary vasodilators are current practices in this population. The use of last-generation NO devices allowed good compliance with recommendations.

\section{KEY POINTS}

Question: This study describes the current use, management, and safety of nitric oxide administered with integrated delivery devices for pulmonary hypertension after cardiac surgery and persistent pulmonary hypertension of the newborn.

Finding: With a median dose at $10 \mathrm{ppm}$ for adults and $20 \mathrm{ppm}$ for children, nitric oxide treatment is often combined with other pulmonary vasodilators, and can be weaned with a low rate of rebound effect.

Meaning: Inhaled nitric oxide administered with these modalities appears safe and complies with the recommendations for various modes of ventilation.

From the *Cardiothoracic Intensive Care Unit, Centre Hospitalier Universitaire de Montpellier, and PhyMedExp, University of Montpellier, CNRS, INSERM, Montpellier, France; †Pediatric Cardiac Intensive Care, Anesthesia and Perfusion Unit, Reference Centre for Complex Congenital Cardiac Disease, Hôpital Necker Enfants Malades, Assistance PubliqueHôpitaux de Paris, Paris, France; $\neq$ Department of Anesthesia and Intensive Care, Centre Hospitalier Universitaire de Nantes, Nantes, France; $\S$ Congenital Cardiac Surgery Unit, Department of Anesthesia and Intensive Care II, Maison du Haut Lévêque - Groupe Hospitalier Sud, Pessac, France; $\|$ Clinique Pasteur, Toulouse, France; INeonatal and pediatric Intensive Care Unit, Centre Hospitalier Universitaire de Montpellier, Montpellier, France; \#Pediatric Intensive Care Unit, Centre Hospitalier Universitaire de Nantes, Nantes, France; ${ }^{* *}$ Cardiovascular Intensive Care Unit, Centre Hospitalier Universitaire Bocage Central, Dijon, France; ††Hôpital Trousseau, Assistance Publique-Hôpitaux de Paris, Paris, France; 执Intensive Care Unit, Centre Hospitalier Universitaire de Liège, Liège, Belgique; $§ \S N e o n a t a l$ Intensive Care Unit, Centre Hospitalier Universitaire de Reims, Reims, France; \|IIAir Copyright (C 2018 International Anesthesia Research Society DOI: 10.1213 /ANE.0000000000002813
Liquide Santé International, Gentily, France; and ITSorbonne Universités, UPMC Univ Paris 06, UMR INSERM 1166, IHU ICAN, and Department of Anesthesiology and Critical Care Medicine, Hôpital Pitié-Salpêtrière, Assistance Publique-Hôpitaux de Paris, Paris, France.

Accepted for publication November 29, 2017.

Funding: This study was funded by Air Liquide Healthcare.

Conflicts of Interest: See Disclosures at the end of the article. 
I nhaled nitric oxide (iNO) induces selective pulmonary vasodilation in cases of pulmonary hypertension $(\mathrm{PH})$ without producing systemic hypotension. ${ }^{1}$ It has been largely used in Europe since 1992, ${ }^{2}$ and obtained the status of drug in France in 2001 and in Belgium in 2008. The European market authorizations (MA) defined 2 labeled indications: persistent $\mathrm{PH}$ of the newborn (PPHN) and treatment of $\mathrm{PH}$ related to cardiac surgery. Both indications have been well described in the scientific literature and have benefited from European recommendations ${ }^{3,4}$ in 2005 about pharmacology, combination with other treatments, monitoring, and delivery. In France and Belgium, many centers administer iNO in a continuous mode through a pressure regulator and flowmeter; this is done both with and without monitoring of $\mathrm{NO}$ and $\mathrm{NO}_{2}$ concentrations. Integrated devices for administration and monitoring have recently been made available in these countries but are used in only one-third of the centers providing iNO therapy.

Despite the absence of any evidence of improvement in outcome $^{5}$ except for PPHN and congenital heart disease, ${ }^{6-8}$ iNO has become a standard of care for $\mathrm{PH}$ in many intensive care units (ICUs), through selective pulmonary vasodilation and a safe pharmacological profile. ${ }^{9}$ Otherwise, few small randomized control trials have compared the efficiency of iNO in PH with other drugs such as prostaglandins or phosphodiesterase inhibitors. ${ }^{10-12}$ Some iNO indications, such as perioperative $\mathrm{PH}$ in cardiac surgery, are recognized by the MA in Europe but are off-label in the United States. A recent propensity matched-cohort study ${ }^{13}$ and systematic review and meta-analysis ${ }^{14,15}$ confirmed that iNO for acute respiratory distress syndrome resulted in a transient improvement in oxygenation but did not reduce mortality and could increase renal impairment. These off-label indications in Europe were not the subject of this study.

Because this is a postapproval study, recruited patients must follow the specifications of MA and only the labeled indications of $\mathrm{iNO}$ in Europe were studied. The aim of this study was to describe in neonatal, pediatric, and adult ICUs the current use of iNO with integrated delivery devices in real life for the indications of PPHN and perioperative $\mathrm{PH}$ in cardiac surgery. The main objectives were to characterize the profile of patients, the overall management of iNO treatment, the occurrence of adverse events (AEs), and to describe the gap with guidelines because no recent and exhaustive data are reported. Furthermore, this is the first study describing the use of iNO with a new generation of integrated delivery and monitoring device in daily practice. These descriptive data should improve iNO therapy management in ICU and provide updated data for future studies.

\section{METHODS}

The POSITIVE (Prospective Observational Study on the use of Inhaled NO administered Through an Integrated deliVEry and monitoring device) study is a multicenter, prospective, observational cohort study held in France and in Belgium and conducted during 1 year in adult, pediatric, and neonatal ICU. Independent French and Belgian ethics committees approved the protocol and data collection was authorized by the National Commission for
Informatics and Liberties. All patients or legal representatives received the study information. According to current national legislation for observational studies in France, the ethic committee waived the need for written informed consent and required only a nonopposition to participation. Written informed consent was obtained from all patients or legal representative in Belgium. This article adheres to the applicable Enhancing the QUAlity and Transparency Of health Research (EQUATOR) guidelines. The objectives and methods of the study were designed before patient enrollment, but this study has been retrospectively registered on Clinical Trials website with the number NCT02821156 by Philippe Pouard as principal investigator on May 20, 2016.

\section{Study Population}

The cohort was studied in 12 investigational centers in France and 2 in Belgium, including 6 cardiac adult centers, 4 pediatric cardiac centers, and 4 neonatal ICU equipped with EZ-KINOX (EKU Elektronik GmbH, Leiningen, Germany), an integrated $\mathrm{NO}$ delivery and monitoring device. EZ-KINOX was used in this study because this device was the first one available in our countries which fulfilled all the specifications required by the European Medicines Agency. This device allows sequential administration of NO, measurement of $\mathrm{NO}$ and $\mathrm{NO}_{2}$ concentrations on the inspiratory limb of the ventilator, and automatic switch from empty to full cylinder, with the same features as INOmax delivery systems (INOmax DSIR or INOvent) which meet Food and Drug Administration guidelines. Furthermore, this device allows the measurement of $\mathrm{NO}$ and $\mathrm{NO}_{2}$ in ambient air. This allows for surveillance of high ambient $\mathrm{NO}$ and $\mathrm{NO}_{2}$ concentrations which may be associated with delivery via high-flow nasal cannula and which may pose a safety risk for caregivers. Participating sites were ICUs trained for the administration of iNO delivered by EZ-KINOX. Perioperative PH was defined by a mean pulmonary arterial pressure (PAP) above $25 \mathrm{~mm} \mathrm{Hg}$ at rest. ${ }^{16}$ The decision to initiate iNO therapy and the choice of dose were at the discretion of the clinician in charge of the patient according to current recommendations on $\mathrm{PH}$ management in neonatology or perioperative cardiac surgery before (ie, in the operating room) or after ICU admission. The management in ICU of PH treatment, ventilation mode, or weaning process was not protocolized and followed routine medical care of each center.

Included patients met the following inclusion criteria: (1) newborns $\geq 34$ weeks of gestational age experiencing hypoxic respiratory failure associated with $\mathrm{PH}$; (2) or patients presenting perioperative $\mathrm{PH}$ associated with cardiac surgery; (3) patients treated with iNO delivered with EZ-KINOX.

Patients who met at least one of the following criteria could not be included in the study: (1) newborns dependent on a right-to-left shunt; (2) infants with a hemodynamically significant patent ductus arteriosus; and (3) newborns with glucose-6-phosphate dehydrogenase deficiency.

\section{Study Treatment}

The study treatment was NO (KINOX 450 ppm-VASOKINOX 450 ppm: NO 450 ppm in nitrogen; Air Liquide Santé France, Gentilly, France) administered by EZ-KINOX. This conformité 
Européenne marked delivery and monitoring device provides reliable, constant, and accurate sequential administration of iNO regardless of the patient age, from newborns to adults and continuous $\mathrm{NO}$ and $\mathrm{NO}_{2}$ monitoring. The device includes alarms to alert in case of NO cessation, $\mathrm{NO}$ overdose (to detect $\mathrm{NO}$ accumulation, threshold arbitrarily set at 2 ppm above the expected dose), or increased inspiratory $\mathrm{NO}_{2}$ value (>0.5 ppm) for early detection of potentially toxic $\mathrm{NO}_{2}$ production. This system is compatible with most of ventilation modes (invasive and noninvasive) and ventilators, to which it is connected either directly (via a RS232 interface for compatible ventilators) or through a flow sensor for synchronization with mechanical ventilation.

\section{Data Collection}

The characteristics of included patients, the diagnosis of $\mathrm{PH}$, and the following parameters were prospectively recorded on case report forms and $\mathrm{AE}$ forms by physicians: description of iNO administration with dosage and treatment duration, associated ventilation mode, weaning procedures, and occurrence of a rebound effect (defined by the association of abrupt increase of pulmonary pressure and desaturation). Monitoring associated with iNO administration, concomitant pulmonary vasodilator treatments, safety data, ICU length of stay, and ICU mortality were also collected. All forms were verified by a monitoring team and analyzed by an independent committee.

\section{Statistical Analysis}

Statistical analyses were performed using SAS software version 9.4 (SAS Institute, Cary, NC). Analyses were only descriptive and expressed as mean and standard deviation or median and interquartile range (25th, 75th percentile) whenever applicable for each subgroup of patients. The 3 subgroups of patients were defined as neonates for PPHN patients, children for pediatric cardiac surgery patients with postoperative $\mathrm{PH}$, and adults for patients with $\mathrm{PH}$ after adult cardiac surgery. Parameters collected were summarized descriptively without comparison between subgroups due to the lack of clinical relevance. Safety was evaluated by describing the occurrences of AE, globally and by subgroup of patients, using percentages and 2-sided exact ClopperPearson $95 \%$ confidence intervals (CIs).

The duration of the study was planned for 1 year of recruitment to limit the likelihood of changes of current practices in iNO usage. Sample size estimation was based on feasibility considerations. Before the study, it was estimated that a maximal number of 250 patients could be included in 1 year. This maximum sample size allowed the reporting of a 2 -sided $95 \% \mathrm{CI}$ of any event occurring with a frequency of $5 \%$ of $(2.8 \%-8.7 \%)$ which is narrow enough to adequately address the research question.

\section{RESULTS}

\section{Patient Characteristics}

A total of 239 consecutive patients were enrolled in 1 year from September 2014 to September 2015. One patient did not sign consent, and 2 presented noninclusion criteria. Therefore 236 patients were included: 38 neonates with PPHN (16.1\%), 81 children (34.3\%), and 117 adult patients $(49.6 \%)$ with $\mathrm{PH}$ after cardiac surgery. Baseline

\begin{tabular}{|c|c|c|c|}
\hline & $\begin{array}{l}\text { PPH Newborn } \\
\quad(\mathrm{N}=\mathbf{3 8})\end{array}$ & $\begin{array}{l}\text { PH Pediatric } \\
(\mathbf{N}=\mathbf{8 1})\end{array}$ & $\begin{array}{l}\text { PH Adults } \\
\text { ( } N=117)\end{array}$ \\
\hline Age (d) & $1(1,3)$ & - & - \\
\hline Age $(y)$ & - & $0.2(0.04,3)$ & $63(53,75)$ \\
\hline Gestational age (wk) & $40(38-40)$ & 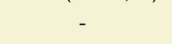 & \\
\hline \multicolumn{4}{|l|}{ Gender, N (\%) } \\
\hline Male & $21(55.3)$ & $50(61.7)$ & $82(70.1)$ \\
\hline Female & $17(44.7)$ & $31(38.3)$ & $35(29.9)$ \\
\hline \multicolumn{4}{|c|}{ Ventilation mode at the beginning of iNO administration } \\
\hline CV (\%) & 78.9 & 92.6 & 94.0 \\
\hline HFOV (\%) & 15.8 & 3.7 & 0 \\
\hline SV or NIV (\%) & 5.3 & 3.7 & 6.0 \\
\hline Including HFNC (\%) & 5.3 & 1.3 & 0 \\
\hline \multicolumn{4}{|c|}{ Ventilation mode at the end of iNO administration } \\
\hline CV (\%) & 70.3 & 19.4 & 60.8 \\
\hline HFOV $(\%)$ & 22.2 & 0 & 0 \\
\hline SV or NIV (\%) & 7.4 & 80.6 & 39.4 \\
\hline Including HFNC (\%) & 7.4 & 4.5 & 2.5 \\
\hline
\end{tabular}

Data are presented as median (25th, 75 th percentile) for continuous variables.

Abbreviations: CV, controlled ventilation; HFNC, high-flow nasal cannula; HFOV, high-frequency oscillatory ventilation; iNO, inhaled nitric oxide; NIV, noninvasive ventilation; $\mathrm{PH}$, pulmonary hypertension; $\mathrm{PPH}$, persistent pulmonary hypertension; SV, spontaneous ventilation.

\begin{tabular}{|c|c|c|c|}
\hline $\begin{array}{l}\text { Pulmonary Hypertension } \\
\text { Diagnosis }\end{array}$ & $\begin{array}{l}\text { PPH Newborn } \\
\quad(\mathrm{N}=\mathbf{3 8})\end{array}$ & $\begin{array}{l}\text { PH Pediatric } \\
\quad(\mathbf{N}=\mathbf{8 1})\end{array}$ & $\begin{array}{l}\text { PH Adults } \\
(\mathrm{N}=117)\end{array}$ \\
\hline $\begin{array}{l}\text { Pulmonary artery } \\
\text { catheterization, } \mathrm{N}(\%)\end{array}$ & $0(0)$ & $18(22.2)$ & $43(36.8)$ \\
\hline Echocardiography, N (\%) & $37(97.4)$ & $76(93.8)$ & $94(80.3)$ \\
\hline $\begin{array}{l}\text { Mean PAP (mm Hg), } \\
\text { mean (SD) }\end{array}$ & $46.3(6.7)$ & $27.2(14.8)$ & $31.6(8)$ \\
\hline $\begin{array}{l}\text { Systolic PAP (mm Hg), } \\
\text { mean (SD) }\end{array}$ & $54.0(18.4)$ & $48.6(22.2)$ & $52.6(14.8)$ \\
\hline
\end{tabular}

Abbreviations: PAP, pulmonary arterial pressure; $\mathrm{PH}$, pulmonary hypertension; $\mathrm{PPH}$, persistent pulmonary hypertension; SD, standard deviation.

demographics and characteristics of the 3 groups of patients are described in Table 1 . The diagnosis process of PH before the initiation of iNO included Doppler and color-Doppler, 2-dimensional echocardiography, and/or measurement of the PAP through a pulmonary artery catheter (Table 2). All the patients had a mean PAP $>25 \mathrm{~mm} \mathrm{Hg}$.

In the adult group, the 4 main circumstances of $\mathrm{PH}$ were mitral valve surgery, combined cardiac surgery for acquired cardiac disease, heart transplantation, and left ventricular assist device implantations. In pediatric cardiac surgery, neonatal surgery and cavopulmonary connections were the main indications for iNO administration. PPHN was mainly associated with respiratory distress syndrome, meconium aspiration syndrome, and diaphragmatic hernia. The iNO was initiated before ICU admission (Table 3 ) in adult patients in the operating room (57\%), and in PPHN patients in the delivery room (38.9\%), but rarely among pediatric cardiac patients $(12.7 \%)$. Patients being treated with iNO were transported to ICU without interruption of this treatment.

\section{Inhaled NO Therapy}

Adults received a median initial iNO dose (10 ppm; 25th, 75th percentile: 10, $15 \mathrm{ppm}$ ) approximately half of the dose 
Data are presented as $\mathrm{N}$ (\%) for categorical variables or median (25th, 75th percentile) for continuous variables.

Abbreviations: ICU, intensive care unit; iNO, inhaled nitric oxide; PH, pulmonary hypertension; PPH, persistent pulmonary hypertension; ppm, parts per million.

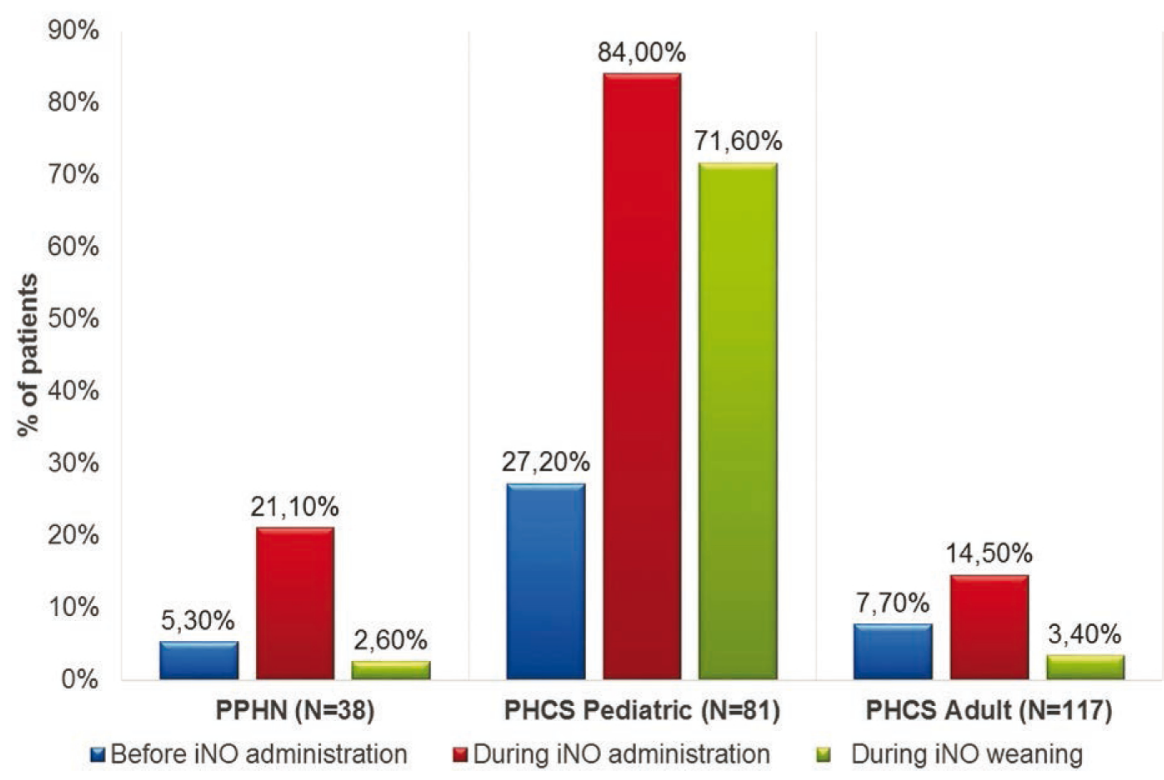

Figure. Patients with at least 1 combined pulmonary vasodilator, presented according to the treatment phase (blue: before iNO administration; red: during iNO administration; green: during iNO weaning) and subgroups. iNO indicates inhaled nitric oxide; PHCS, pulmonary hypertension in cardiac surgery; PPHN, persistent pulmonary hypertension of the newborn.

in neonates (17 ppm; 25th, 75th percentile: 11, $20 \mathrm{ppm}$ ) and children (20 ppm; 25th, 75th percentile: 18, $20 \mathrm{ppm}$ ). The iNO administration was gradually weaned on a median of 3.1 days in newborns, 3.9 days in children, and 3.8 days in adults (Table 3 ). At the onset of iNO delivery with EZ-KINOX, most of the patients were ventilated using a controlled ventilation mode in $78.9 \%, 92.6 \%$, and $94.0 \%$ of neonates, children, and adults, respectively (Table 1). Highfrequency oscillatory ventilation was used in $15.8 \%$ of neonates. Throughout the course of delivery, the ventilation mode was switched to spontaneous ventilation or noninvasive ventilation including nasal high-flow cannula in $7.4 \%$, $80.6 \%$, and $39.3 \%$ in neonates, children, and adults, respectively. The connections between EZ-KINOX and ventilators were a RS232 interface in $52 \%$ or a flow sensor in $26 \%$ of cases, allowing synchronization with ventilation, and a manual mode was used in $22 \%$.

Other pulmonary vasodilators were combined before, during, and after inhalation of $\mathrm{NO}$, including milrinone, sildenafil, and/or levosimendan (Figure) mainly for the pediatric cardiac surgery population (maximum rate of $84 \%$ ). The dose was gradually decreased before definitive withdrawal of iNO in $85 \%$ of cases and the median lowest doses of iNO were 3 ppm in neonates, 5 ppm in children and adults (Table 3 ).

\section{Adverse Events}

Among the 236 patients, 89 AE were reported and 53 patients $(22.5 \%$ [95\% CI, $17.3 \%-28.3 \%])$ had at least 1
AE during the study but only 17 patients $(7.2 \%$ [95\% CI, $4.3 \%-11.3 \%]$ ) experienced an AE related to iNO (Table 4). All AE are listed in Supplemental Digital Content, Table 1, http://links.lww.com/AA/C238. The most frequent considered as not related to iNO were cardiac disorders, respiratory disorders, and multiorgan failure. Acute kidney injury was reported in 5 adult patients (4.3\%) but not in neonates and children. AE related to iNO included rebound effect $(2.6 \%$ [95\% CI, $0.1 \%-13.8 \%$ ] in neonates, $1.2 \%$ [95\% CI, $0.0 \%-6.7 \%$ ] in children, and 3.4\% [95\% CI, 0.9\%-8.5\%] in adults), hypoxemia (5.3\% [95\% CI, 0.6\%-17.7\%], 0\% [95\% CI, 0\%-4.5\%], and 0.9\% [95\% CI, 0.0\%-4.7\%] respectively), and methemoglobinemia above 2.5\% (7.9\% [95\% CI, $1.7 \%-21.4 \%$ ], $0 \%$ [95\% CI, 0\%-4.5\%], and $1.7 \%$ [95\% CI, $0.2 \%-6.0 \%]$, respectively). Nevertheless, methemoglobinemia was monitored only for 25 neonates $(65.8 \%), 7$ children $(8.6 \%)$, and 30 adults $(25.6 \%)$. All these AE related to iNO recovered without sequelae.

The $\mathrm{NO}_{2}$ generated by contact between $\mathrm{NO}$ and oxygen during iNO administration was above $0.5 \mathrm{ppm}$ in $17 \%$ of pediatric cases, $1 \%$ of adult cases and never observed in the neonatal population. The monitoring of ambient $\mathrm{NO}$ and $\mathrm{NO}_{2}$ in room air has never shown any increase $>0.5 \mathrm{ppm}$ of ambient $\mathrm{NO}$ or $\mathrm{NO}_{2}$ values during the study, guaranteeing the safety of the professionals working around the patient.

\section{Outcomes}

The main reason for definitive discontinuation of iNO therapy was a sufficient clinical effect with successful weaning 
Table 4. End of Treatment, Outcome, and Safety of Nitric Oxide Therapy

\begin{tabular}{|c|c|c|c|}
\hline & $\begin{array}{c}\text { PPH } \\
\text { Newborn } \\
(\mathrm{N}=38)\end{array}$ & $\begin{array}{c}\text { PH } \\
\text { Pediatric } \\
(\mathrm{N}=\mathbf{8 1})\end{array}$ & $\begin{array}{c}\text { PH } \\
\text { Adults } \\
(\mathrm{N}=117)\end{array}$ \\
\hline $\begin{array}{l}\mathrm{NO}_{2}>0.5 \mathrm{ppm} \\
\text { Reason for definitive } \\
\text { discontinuation }\end{array}$ & $0(0)$ & $14(17.3)$ & $1(0.9)$ \\
\hline Missing data & $\mathrm{O}(0)$ & $3(3.7)$ & $4(3.4)$ \\
\hline Sufficient clinical effect & $32(84.2)$ & 77 (95.1) & 99 (84.6) \\
\hline Occurrence of an $\mathrm{AE}$ & $6(15.8)$ & $1(1.2)$ & $11(9.4)$ \\
\hline Lack of efficacy & $\mathrm{O}(0)$ & $0(0)$ & $3(2.6)$ \\
\hline \multicolumn{4}{|l|}{ Weaning phase } \\
\hline $\begin{array}{l}\text { Progressive decrease } \\
\text { of NO dosage }\end{array}$ & $29(76.3)$ & $76(93.8)$ & $94(81)$ \\
\hline Rebound effect & $1(26)$ & $1(1.2)$ & $4(3.4)$ \\
\hline \multicolumn{4}{|l|}{$A E$ (safety) } \\
\hline At least $1 \mathrm{AE}$ & $13(34.2)$ & $5(6.2)$ & 35 (29.9) \\
\hline Total number of events ${ }^{a}$ & 15 & 6 & 68 \\
\hline $\begin{array}{r}\text { Patient with at least } 1 \\
\text { AE related to NO }\end{array}$ & $6(15.8)$ & $1(1.2)$ & $10(8.5)$ \\
\hline Rebound effect & $1(2.6)$ & $1(1.2)$ & $4(3.4)$ \\
\hline $\begin{array}{l}\text { Patients with MetHb } \\
\text { monitoring }\end{array}$ & $25(65.8)$ & $7(8.6)$ & $30(25.6)$ \\
\hline MetHb $>2.5 \%^{\mathrm{b}}$ & $3(12)$ & $0(0)$ & $2(6.7)$ \\
\hline ICU length of stay (d) & $9(8,15)$ & $8(6,15)$ & $10(6,16)$ \\
\hline ICU mortality & $3(7.9)$ & $5(6.2)$ & $26(22.2)$ \\
\hline
\end{tabular}

Data are presented as $\mathrm{N}(\%)$ for categorical variables or median (25th, 75 th percentile) for continuous variables.

Abbreviations: AE, adverse event; ICU, intensive care unit; MetHb, methemoglobinemia; NO, nitric oxide; $\mathrm{PH}$, pulmonary hypertension; $\mathrm{PPH}$ persistent pulmonary hypertension.

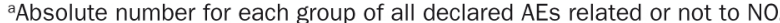

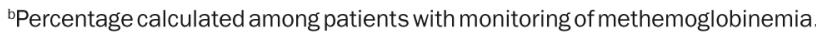

in $88 \%$ of cases $(84.2 \%$ in neonates, $95.1 \%$ in children, and $84.6 \%$ in adults). The other reasons were the occurrence of AE or lack of efficacy as shown in Table 4. In the adult group, iNO was stopped in 3 cases for a lack of efficacy without any hemodynamical improvement. Median (25th, 75th percentile) ICU stay was respectively $9(8,15)$ days, $8(6,15)$ days, and $10(6,22)$ days, and ICU mortality was $7.9 \%, 6.2 \%$, and $22.2 \%$ for neonates, children, and adults.

\section{DISCUSSION}

After several decades of use, iNO is currently considered as a standard of care in many countries for $\mathrm{PH}$ in cardiac surgery and PPHN. ${ }^{6-9,17,18}$ Considering diversity in age, $\mathrm{PH}$ level, circumstances for treatment, and ventilation mode, this prospective study described the current ICU usage of iNO in specialized neonatal and cardiac centers.

Because of the potential side effects ${ }^{19}$ and the $\operatorname{cost}^{20}$ of the drug, the iNO indications should be carefully selected in case of prolonged use. Abrupt discontinuation of iNO delivery, for any reason can cause a rebound effect with acute $\mathrm{PH}^{21-23}$ and iNO overdose can lead to toxic $\mathrm{NO}_{2}$ and methemoglobin production. ${ }^{23}$ Therefore, delivery systems need to be reliable for iNO delivery and $\mathrm{NO} / \mathrm{NO}_{2}$ monitoring. ${ }^{24,25}$ New generations of $\mathrm{NO}$ delivery devices meet these requirements and may prevent any discontinuation of drug delivery during transport or cylinders exchange. This is the first study reporting clinical use of these devices in Europe. The modes of ventilation during NO therapy differed between the 3 groups and the treatment times. Invasive modes of ventilation were the most common at the initiation of the treatment and high-frequency oscillatory ventilation was reserved to PPHN. During the weaning phase, ventilation modes were less invasive or controlled, especially in cardiac patients with spontaneous ventilation or noninvasive ventilation (including nasal high-flow therapy) for most of them. In this study, the new generation of devices allowed easy adaptation to different modes of ventilation.

Some specificities were observed regarding the different population groups. In this study, the diagnosis of $\mathrm{PH}$ was always performed by echocardiography in neonates experiencing PPHN as described in literature, ${ }^{26-28}$ and iNO therapy was often started before ICU admission either in the delivery room or during transport. Therefore, the delivery system and NO cylinders should be adapted to be used safely during transport. In pediatric cardiac surgery, $\mathrm{PH}$ was often diagnosed before the surgical procedure by echocardiography and/or direct PAP measurement by catheterization ${ }^{29}$ and $\mathrm{iNO}$ was mainly initiated in ICU after the procedure. In this group, the mean PAP level $(27.2 \pm$ $14.8 \mathrm{~mm} \mathrm{Hg}$ for this group) was lowered in case of cavopulmonary connection where iNO was used to reduce the transpulmonary gradient more than to reverse a $\mathrm{PH}$ crisis. ${ }^{3}$ Consistent with published data, ${ }^{30}$ iNO was almost always combined with oral sildenafil. In this population, despite a higher dose, the occurrence of adverse effects was very low. The specificities of the adult population were the necessity for iNO administration in the operating room before ICU admission in almost $60 \%$ of cases, and the limited requirement of additional pulmonary vasodilators. Surprisingly, the initial dose of NO was about 10 ppm without the need to increase the dose during treatment. This is less than the dose mentioned in the American and European recommendations which allow a dose up to $40 \mathrm{ppm} .{ }^{4}$ Only 3 patients, $2.6 \%$ of the adult group, did not respond to NO therapy and none in neonatal and pediatric groups. Some reports show a $20 \%$ rate of nonresponders. ${ }^{31,32}$ The low rate of nonresponders may result from the strict use of iNO in labeled indications and/or the synergistic effect of the combination with other pulmonary vasodilators.

For the 3 populations, the results show that the weaning procedure included a stepwise progressive discontinuation of iNO delivery, avoiding a rebound effect of $\mathrm{PH}$ characterized by an acute increase of pulmonary vascular resistance, hypoxia, and hemodynamic impairment and caused by transient depletion of intrinsic cyclic guanosine monophosphate. Kageyama et $\mathrm{al}^{33}$ showed that the final concentration of $<2$ ppm contributes to successful discontinuation of iNO therapy in pediatric patients after cardiac surgery. As suggested by Namachivayam et al, ${ }^{30}$ combination with other pulmonary vasodilators may prevent the occurrence of a rebound effect. In a recent expert consensus on pediatric $\mathrm{PH}_{,}^{34}$ oral sildenafil is mentioned as reasonable to facilitate weaning from iNO. The low $\mathrm{PH}$ rebound rate observed in our study (1.2\%) could result from the wide application of 1 or 2 of these strategies. In this study, iNO was administered through a consistent delivery device and $82.4 \%$ of the patients did not experience any AEs. The most common safety concern was $\mathrm{NO}_{2}$ formation in pediatric cardiac surgery which can be explained by the high fraction of inspired oxygen usually required after pediatric cardiac procedures. ${ }^{35}$ Methemoglobin excess is one of the main side effect observed in the neonatal population; 
however, the reduction of the iNO dose allowed rapid recovery without clinical impact. This issue, also described in children with congenital heart disease, ${ }^{36}$ was not observed in our study but methemoglobin monitoring was not systematically performed in pediatric and adult ICU as requested in the recommendations. ${ }^{4}$ This practice should be maintained especially for highest iNO doses.

Compared with the former retrospective survey conducted in 1997 in 21 European countries and based only on questionnaires, ${ }^{8}$ iNO therapy has changed in several aspects. The 1997 survey was conducted before the establishment of clear recommendations. In 1997, 62\% of the physicians did not consider the PAP threshold, and administered more than $40 \mathrm{ppm}$ in $43 \%$ of cases compared to $20 \mathrm{ppm}$ or less in all cases of our observations. Moreover, $51 \%$ of cases received iNO in a continuous mode throughout the respiratory cycle, whereas in the POSITIVE study, iNO was administered during the inspiratory phase $(78 \%$ of synchronized connections to ventilators). In France and Belgium, the cost of iNO is based on the volume of gas used, and therefore synchronization of gas delivery with invasive or noninvasive mechanical ventilation would be expected to reduce waste of this expensive gas compared to bolus delivery. Differences in indications (in 1997, the main indication for iNO therapy was acute respiratory distress syndrome) and in the modes of administration may probably explain a better response to iNO therapy (10\%-20\% nonresponder vs $0 \%-2.6 \%)$ and a huge decrease of the occurrence of incidents and complications (9\% excessive bleeding vs $0 \% ; 6 \%$ acute pulmonary edema vs $0 \% ; 20 \%$ rebound effect vs $1.2 \%-3.4 \%$ ).

\section{Study Limitations}

This study provides a snapshot in time and presents several bias and confounding effects such as representability of the sample and selection bias. Main limitations are the selection of centers using EZ-KINOX device which did not represent most of NO users and the strictly restriction of MA indication (excluding off-label usage of the product in Europe). The results may not be generalizable to other NO delivery systems and to these off-label indications. Of note, despite a common use especially in the pediatric population, the indication of iNO for PH in cardiac surgery is off-label in the United States due to a lack of definitive evidence. ${ }^{37}$ The heterogeneity of practices in the use and management of iNO was another limitation. However, the objective of this observational study was to describe current practices and the only constraint in the study protocol was to use the EZ-KINOX device. Data on hemodynamic and echocardiography were not required after initiation of iNO therapy and the assessment of "sufficient clinical effect" or "lack of efficacy" could be subjective but are the reflect of medical practices.

\section{CONCLUSIONS}

This large prospective study in 236 patients describes the current use pattern of iNO and confirms the safety of iNO in the study population with a low rate of rebound effect. Gradually withdrawal of $\mathrm{NO}$ and combination with other pulmonary vasodilators are current practices in this population. Confidence in the delivery and monitoring devices is likely to reduce the maximum administered dose of iNO and to secure transportation and change of NO cylinders without discontinuation. While there have been improvements in delivery and monitoring of iNO therapy within the last 2 decades, further controlled randomized trials and international registry data will be needed to define appropriate indications for use of iNO and to refine the current guidelines.

\section{ACKNOWLEDGMENTS}

We would like to thank all the POSITIVE (Prospective Observational Study on the use of Inhaled NO administered Through an Integrated deliVEry and monitoring device) investigators for their tremendous work. We would also like to thank the various persons from Air Liquide Paris Saclay research center who were involved in monitoring and analysis of the study, especially Marylyn Labart and Sylvie Laroche, who actively supported the study.

\section{DISCLOSURES}

Name: Philippe Gaudard, MD.

Contribution: This author helped in acquisition and interpretation of data, and drafted and provided an extensive revision of the article.

Conflicts of Interest: None.

Name: Claudio Barbanti, MD.

Contribution: This author helped in acquisition, analysis, and interpretation of data, and drafted the article.

Conflicts of Interest: C. Barbanti has been invited by Air Liquide Healthcare to present the results of the study to European Association of Paediatric Societies Congress in Geneva and Pediatrics International Conferences Convention in Toronto.

Name: Bertrand Rozec, PhD.

Contribution: This author helped with acquisition of data and with the final version of the article.

Conflicts of Interest: None.

Name: Philippe Mauriat, MD.

Contribution: This author helped with acquisition of data and with the final version of the article.

Conflicts of Interest: None.

Name: Mimoun M'rini, MD.

Contribution: This author helped with acquisition of data and with the final version of the article.

Conflicts of Interest: None.

Name: Gilles Cambonie, PhD.

Contribution: This author helped with acquisition of data and with the final version of the article.

Conflicts of Interest: None.

Name: Jean Michel Liet, MD.

Contribution: This author helped with acquisition of data and with the final version of the article.

Conflicts of Interest: None.

Name: Claude Girard, PhD.

Contribution: This author helped with acquisition of data and with the final version of the article.

Conflicts of Interest: None.

Name: Pierre Louis Leger, PhD.

Contribution: This author helped with acquisition of data and with the final version of the article.

Conflicts of Interest: None.

Name: Ziad Assaf, MD.

Contribution: This author helped with acquisition of data and with the final version of the article.

Conflicts of Interest: None.

Name: Pierre Damas, PhD.

Contribution: This author helped with acquisition of data and with the final version of the article.

Conflicts of Interest: None.

Name: Gauthier Loron, MD.

Contribution: This author helped with acquisition of data and with the final version of the article. 
Conflicts of Interest: None.

Name: Laurent Lecourt, PharmD.

Contribution: This author helped analyze and interpret the data, and draft the manuscript.

Conflicts of Interest: L. Lecourt is employed by Air Liquide Healthcare.

Name: Julien Amour, PhD.

Contribution: This author helped with acquisition of data and with the final version of the article.

Conflicts of Interest: None.

Name: Philippe Pouard, MD.

Contribution: This author helped design the study, helped with acquisition, analysis, and interpretation of data, and helped draft the article.

Conflicts of Interest: P. Pouard reports personal fees from Air Liquide Healthcare.

\section{REFERENCES}

1. Frostell C, Fratacci MD, Wain JC, Jones R, Zapol WM. Inhaled nitric oxide. A selective pulmonary vasodilator reversing hypoxic pulmonary vasoconstriction. Circulation. 1991;83:2038-2047.

2. Girard C, Lehot JJ, Pannetier JC, Filley S, Ffrench P, Estanove S. Inhaled nitric oxide after mitral valve replacement in patients with chronic pulmonary artery hypertension. Anesthesiology. 1992;77:880-883

3. Barr FE, Macrae D. Inhaled nitric oxide and related therapies Pediatr Crit Care Med. 2010;11(suppl 2):S30-S36.

4. Germann P, Braschi A, Della Rocca G, et al. Inhaled nitric oxide therapy in adults: European expert recommendations. Intensive Care Med. 2005;31:1029-1041.

5. Elmi-Sarabi M, Deschamps A, Delisle S, et al. Aerosolized vasodilators for the treatment of pulmonary hypertension in cardiac surgical patients: a systematic review and meta-analysis. Anesth Analg. 2017;125:393-402.

6. Roberts JD Jr, Fineman JR, Morin FC III, et al. Inhaled nitric oxide and persistent pulmonary hypertension of the newborn. The Inhaled Nitric Oxide Study Group. N Engl J Med. 1997;336:605-610.

7. Davidson D, Barefield ES, Kattwinkel J, et al. Inhaled nitric oxide for the early treatment of persistent pulmonary hypertension of the term newborn: a randomized, double-masked, placebo-controlled, dose-response, multicenter study. The I-NO/ PPHN Study Group. Pediatrics. 1998;101:325-334.

8. Gorenflo M, Gu H, Xu Z. Peri-operative pulmonary hypertension in paediatric patients: current strategies in children with congenital heart disease. Cardiology. 2010;116:10-17.

9. Beloucif S, Payen D. A European survey of the use of inhaled nitric oxide in the ICU. Working Group on Inhaled NO in the ICU of the European Society of Intensive Care Medicine. Intensive Care Med. 1998;24:864-877.

10. Fattouch K, Sbraga F, Bianco G, et al. Inhaled prostacyclin, nitric oxide, and nitroprusside in pulmonary hypertension after mitral valve replacement. I Card Surg. 2005;20:171-176.

11. Winterhalter M, Simon A, Fischer S, et al. Comparison of inhaled iloprost and nitric oxide in patients with pulmonary hypertension during weaning from cardiopulmonary bypass in cardiac surgery: a prospective randomized trial. J Cardiothorac Vasc Anesth. 2008;22:406-413.

12. Matamis D, Pampori S, Papathanasiou A, et al. Inhaled NO and sildenafil combination in cardiac surgery patients with out-of-proportion pulmonary hypertension: acute effects on postoperative gas exchange and hemodynamics. Circ Heart Fail. 2012;5:47-53.

13. Ruan SY, Wu HY, Lin HH, Wu HD, Yu CI, Lai MS. Inhaled nitric oxide and the risk of renal dysfunction in patients with acute respiratory distress syndrome: a propensity-matched cohort study. Crit Care. 2016;20:389.

14. Gebistorf F, Karam O, Wetterslev J, Afshari A. Inhaled nitric oxide for acute respiratory distress syndrome (ARDS) in children and adults. Cochrane Database Syst Rev. 2016.CD002787. doi:10.1002/14651858.CD002787.pub3.

15. Afshari A, Brok J, Møller AM, Wetterslev J. Inhaled nitric oxide for acute respiratory distress syndrome and acute lung injury in adults and children: a systematic review with meta-analysis and trial sequential analysis. Anesth Analg. 2011;112:1411-1421.

16. Hoeper MM, Bogaard HJ, Condliffe R, et al. Definitions and diagnosis of pulmonary hypertension. J Am Coll Cardiol. 2013;62:D42-D50.

17. Fernandes JL, Sampaio RO, Brandão $\mathrm{CM}$, et al. Comparison of inhaled nitric oxide versus oxygen on hemodynamics in patients with mitral stenosis and severe pulmonary hypertension after mitral valve surgery. Am J Cardiol. 2011;107:1040-1045.

18. Benedetto M, Romano R, Baca G, et al. Inhaled nitric oxide in cardiac surgery: Evidence or tradition? Nitric Oxide. 2015;49:67-79.

19. Troncy E, Francoeur M, Blaise G. Inhaled nitric oxide: clinical applications, indications, and toxicology. Can J Anaesth. 1997;44:973-988.

20. Kilchemmann Fuentes C, Vallejos Vallejos C, Román Navarro A. [Cost effectiveness and budget impact analysis of inhaled nitric oxide in a neonatal unit from the perspective of the public health system]. Rev Chil Pediatr. 2016;87:463-467.

21. Cueto E, López-Herce J, Sánchez A, Carrillo A. Life-threatening effects of discontinuing inhaled nitric oxide in children. Acta Paediatr. 1997;86:1337-1339.

22. Lavoie A, Hall JB, Olson DM, Wylam ME. Life-threatening effects of discontinuing inhaled nitric oxide in severe respiratory failure. Am J Respir Crit Care Med. 1996;153:1985-1987.

23. Christenson I, Lavoie A, O'Connor M, Bhorade S, Pohlman A, Hall JB. The incidence and pathogenesis of cardiopulmonary deterioration after abrupt withdrawal of inhaled nitric oxide. Am J Respir Crit Care Med. 2000;161:1443-1449.

24. Montgomery FJ, Berssenbrugge AD. Inhaled nitric oxide delivery and monitoring. J Clin Monit Comput. 1999;15:325-335.

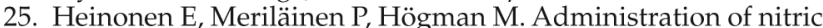
oxide into open lung regions: delivery and monitoring. $\mathrm{Br} J$ Anaesth. 2003;90:338-342.

26. Aggarwal S, Natarajan G. Echocardiographic correlates of persistent pulmonary hypertension of the newborn. Early Hum Dev. 2015;91:285-289.

27. Bendapudi P, Rao GG, Greenough A. Diagnosis and management of persistent pulmonary hypertension of the newborn. Paediatr Respir Rev. 2015;16:157-161.

28. Jain A, McNamara PJ. Persistent pulmonary hypertension of the newborn: Advances in diagnosis and treatment. Semin Fetal Neonatal Med. 2015;20:262-271.

29. Roth TS, Aboulhosn JA. Pulmonary hypertension and congenital heart disease. Cardiol Clin. 2016;34:391-400.

30. Namachivayam P, Theilen U, Butt WW, Cooper SM, Penny DJ, Shekerdemian LS. Sildenafil prevents rebound pulmonary hypertension after withdrawal of nitric oxide in children. Am J Respir Crit Care Med. 2006;174:1042-1047.

31. Morel AA, Shreck E, Mally PV, Kim Y, Bailey SM, Wachtel EV. Clinical characteristics and factors associated with term and late preterm infants that do not respond to inhaled nitric oxide (iNO). J Perinat Med. 2016;44:663-668.

32. Post MC, Janssens S, Van de Werf F, Budts W. Responsiveness to inhaled nitric oxide is a predictor for mid-term survival in adult patients with congenital heart defects and pulmonary arterial hypertension. Eur Heart J. 2004;25:1651-1656.

33. Kageyama K, Shime N, Hirose M, Hiramatsu N, Ashida H, Hashimoto S. Factors contributing to successful discontinuation from inhaled nitric oxide therapy in pediatric patients after congenital cardiac surgery. Pediatr Crit Care Med. 2004;5:351-355.

34. Kaestner M, Schranz D, Warnecke G, Apitz C, Hansmann G, Miera O. Pulmonary hypertension in the intensive care unit. Expert consensus statement on the diagnosis and treatment of paediatric pulmonary hypertension. The European Paediatric Pulmonary Vascular Disease Network, endorsed by ISHLT and DGPK. Heart. 2016;102(suppl 2):ii57-ii66.

35. Petit PC, Fine DH, Vásquez GB, Gamero L, Slaughter MS, Dasse KA. The pathophysiology of nitrogen dioxide during inhaled nitric oxide therapy. ASAIO J. 2017;63:7-13.

36. Hermon MM, Burda G, GolejJ, et al. Methemoglobin formation in children with congenital heart disease treated with inhaled nitric oxide after cardiac surgery. Intensive Care Med. 2003;29:447-452.

37. Kuch BA, Saville AL, Sanchez De Toledo J, Venkataraman ST. Inhaled pulmonary vasodilators: are there indications within the pediatric ICU? Respir Care. 2017;62:678-698 